\title{
Poisoning by Senecio brasiliensis in Horses in Northern Rio Grande do Sul
}

\author{
Stéfano Leite Dau' ${ }^{1}$ Tanise Policarpo Machado², Ezequiel Davi dos Santos ${ }^{2}$, Diorges Henrique Setim², \\ Eduardo Rebelato Sakis ${ }^{2}$, Leonardo Porto Alves ${ }^{3} \&$ Adriana Costa da Motta ${ }^{2}$
}

\begin{abstract}
Background: In various regions of Brazil, horses and cattle are considered the most susceptible animals to plant poisoning. The plants of the genus Senecio are the most important in Rio Grande do Sul because they have the active principle known as the pyrrolizidine alkaloid. Its diagnosis is made through epidemiology, clinical signs and histopathological analysis, either of the tissues obtained by biopsy or necropsy. The objective of this study was to report and characterize the epidemiological, clinical and anatomopathological findings of three cases of natural poisoning by Senecio brasiliensis in horses assisted at the Hospital Veterinário (HV) of the Universidade de Passo Fundo (UPF).

Cases: Three traction horses, two males and one female, were admitted at the HV-UPF for clinical care. The animals were presenting anorexia, weight loss, dysmetria, proprioceptive deficit and signs suggestive of colic. The epidemiological study revealed that the sites where these animals were located were infested by Senecio brasiliensis. The support therapy used for equine colic in all three cases was unsuccessful. One of the animals died and the other two were euthanized, all three of them being reffered for necropsy. The post-mortem findings were mainly found in the liver, which showed accentuation of the lobular pattern and the appearance of nutmeg. During necropsy, fragments of organs from thoracic and abdominal cavities and central nervous system were collected and fixed in $10 \%$ buffered formalin. Subsequently, the samples were processed chemically, submitted to cuts of five micrometers of thickness and stained with hematoxylin and eosin for microscopic analysis. Microscopically, the liver of all three horses presented megalocytosis, fibrosis and bile ducts hyperplasia. In the central nervous system, spongiosis and the presence of Alzheimer type II astrocytes were observed. Thus, through the association of information, the diagnosis of poisoning by Senecio brasiliensis was achieved.

Discussion: The diagnosis of natural poisoning by Senecio brasiliensis was obtained through the epidemiological survey that showed S. brasiliensis in pastures where all three horses were allocated. Cases of intoxication by S. brasieliensis in cattle are more frequent than in equines, although both species are considered the most susceptible. In horses, the main clinical manifestations observed include neurological disorders, apathy, anorexia, dysphagia, weight loss, subcutaneous edema and icterus. The clinical signs presented by the equines suggested initial signs of colic syndrome, although anorexia, weight loss, dysmetria and proprioceptive deficit are commonly observed in pyrrolizidine alkaloid poisoning in the liver, both in cattle and horses. The pyrrolizidine alkaloids present in the genus Senecio that become toxic when biotransformed in the liver into a pyrrholic form highly reactive that inhibits cell mitosis and leads to the onset of megalocytosis, cell death and liver fibrosis. The necropsy findings and histopathology were characteristic of poisoning in equines, since the predominant macroscopic lesions in the liver were hepatomegaly and accentuation of lobular pattern, whereas microscopically, there was a predominance of hepatic fibrosis, megalocytosis, spongiosis and the incidence of Alzheimer's type II astrocytes in the brain. These lesions are observed both in natural and in experimental cases of poisoning in horses. Thus, through the ante-mortem and complete post-mortem evaluation of the three equines, it was possible to establish the occurrence of natural poisoning by Senecio brasiliensis in Northern Rio Grande do Sul, as well as to characterize the epidemiological, clinical and anatomopathological findings of poisoning in this species.
\end{abstract}

Keywords: production animals, horses, poisoning, pyrrolizidine alkaloids, Senecio brasiliensis. 


\section{INTRODUCTION}

Plants of the genus Senecio contain pyrrolizidine alkaloids (PAs), with Senecio brasiliensis being the most important species in Rio Grande do Sul $[1,13]$. Individual factors of cattle and horses, as well as the variety and quantity of PAs ingested directly interfere with the onset of intoxication manifestation $[1,10,12,14]$. The animals may have ingested the plant in seasons with lack of forage and emergence of Senecio spp., and exhibit symptomatology during seasons with abundance of forage and plant decline [2].

Cases of intoxication by Senecio spp. in cattle are more frequent than in equines, although the two species are considered the most susceptible [14]. There are few reports of cases of natural intoxication [1] and experimental [10] in horses in Brazil, where the disease usually presents a chronic clinical course, but cases of acute intoxication may also occur [7,14].

Intoxicated animals usually present with apathy, anorexia, dysphagia, emaciation, subcutaneous edema, icterus and neurological disorders $[1,10,11,14]$, and post-mortem examination shows lesions in the liver and central nervous system including fibrosis, megalocytosis, spongiosis and appearance of Alzheimer's type II astrocytes [7,14]. To date, this intoxication has not been diagnosed in the area covered by the Animal Pathology Laboratory of the University of Passo Fundo. Thus, the present study aims to report the natural intoxication by Senecio brasiliensis in equines, characterizing its epidemiological, clinical and anatomopathological aspects.

\section{CASES}

The cases occurred in three horses used for traction, in the city of Passo Fundo, Northern RS, two males and one female. Horse A was one year old, while horse $\mathrm{B}$ and $\mathrm{C}$ were five and twenty three years old, respectively. The three animals were admitted at the Hospital Veterinário of UPF (HV-UPF) for clinical care in the months of December, April and May. In all cases the presence of Senecio brasiliensis was confirmed in the enclosure where the animals were found.

The three horses were presenting clinical signs of anorexia, progressive weight loss, apathy, poor body condition score and abdominal discomfort suggestive of colic. Equine A was also exhibiting staggering pace and pressuring head and body against objects, characterizing a neurological picture of proprioceptive deficit, and equine $\mathrm{C}$ showed signs of depression (Figure 1A).
The clinical evolution of the three cases ranged from one to 15 days, and although the patients were receiving supportive therapy for the signs suggestive of colic syndrome, there was no improvement in any of the horses. Equine A died 15 days after hospitalization and horses B and C, due to the severity of the clinical condition, were submitted to euthanasia after the consent of the owners. The corpses were referred for necropsy at the HV-UPF Laboratório de Patologia Animal.

At necropsy, the liver of the three animals presented an accentuation of the lobular pattern (Figure 1B) and firm consistency at cut, and equine A presented jaundice. Equines A and B also presented ascites and only equine B showed edema in intestines' serosa. During necropsy fragments of organs from thoracic and abdominal cavities and the complete central nervous system were collected and fixed in $10 \%$ buffered formalin. Subsequently, the samples were processed chemically by conventional methods and submitted to cuts of five micrometers of thickness. Afterwards, the sections were stained with hematoxylin and eosin for microscopic analysis.

Microscopically, in the three horses, it was observed loss of liver's parenchyma architecture, marked diffuse megalocytosis associated with periportal fibrosis and bile duct hyperplasia (Figure 1C-D), as well as intra-canalicular and intrahepatic cholestasis. Moderate multifocal spongiosis (Figure 1E) was observed in the brain with Alzheimer type II astrocytes in the gray matter (Figure 1F) and white matter, as well as in the white matter of the cerebellum.

\section{DISCUSSION}

The natural poisoning by Senecio brasiliensis is more common in cattle than in equines, since horses receive supplementation during periods of low pasture availability, besides the fact of this plant being less palatable for this species [3]. Cases of Senecio brasiliensis poisoning in horses have not been described in the Northern Rio Grande do Sul (RS).

In the studied cases, it is suggested that the poisoning occurred because the animals were allocated in fields with little forage availability. In all the reported cases, the Senecio brasiliensis plant species was identified as an invasive toxic plant at the grazing site, with consequent consumption of PAs. The clinical evolution of poisoning observed in the reported cases corroborates with those already described for equines, 


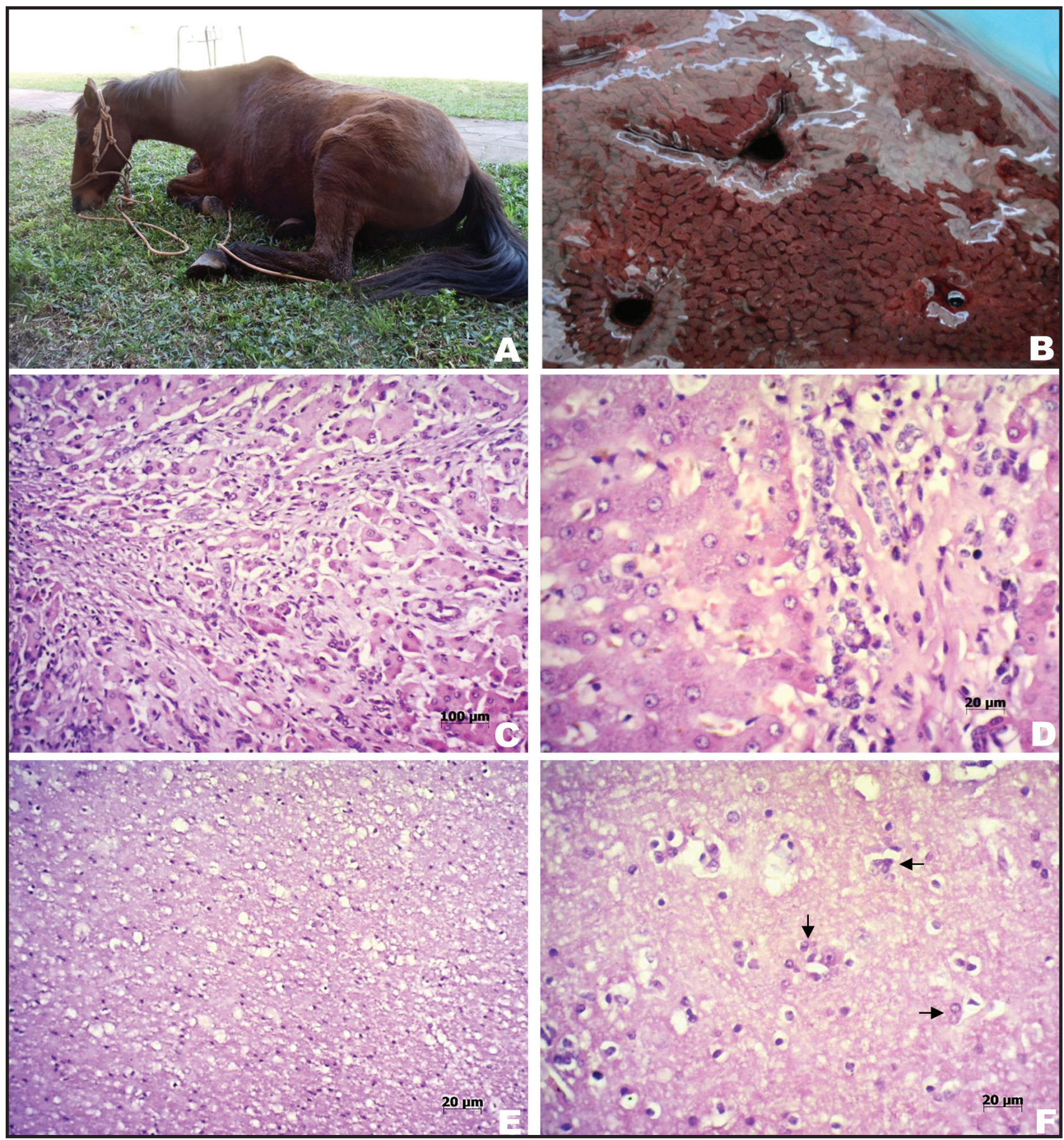

Figure 1. Poisoning by Senecio brasiliensis in horses. A- Equine C presenting clinical picture of abdominal discomfort and depression. B- Equine B, liver surface cut, accentuation of lobular pattern. C- Equine A, liver, loss of parenchyma architecture, periportal fibrosis and bile duct hyperplasia [HE; $\mathrm{x} 100]$. D- Equine B, liver, megalocytosis, fibrosis and bile duct hyperplasia [HE; x400]. E- Equine C, brain, gray matter with spongiosis [HE; x200]. F- Equine C, brain, gray matter, presence of Alzheimer type II astrocytes (arrows) [HE; X400].

where the clinical course can vary from one to 30 days and clinical sings arise from weeks to months after the ingestion of the plant [2,6,10].

In RS, poisoning of bovines and horses by PAs occurs mainly in the months of May to August. At this period the plants with this toxic active principle, mainly those of the genus Senecio, are in full bloom and flowering in potentially invaded fields. Additionally, this period coincides with the low availability of forage at grazing sites [2,14]. Intoxication can also occur by accidental ingestion of the plant or seed in contaminated hay and silage, since the plant does not lose its toxicity, even after desiccation [4]. The animals of the present study showed clinical signs 
during a period in which Senecio brasiliensis was starting its flowering process in the infested fields. However, it should be noted that PAs poisoning is chronic, most of the times, and it is possible that the horses have consumed the plant in months before the clinical manifestation.

The clinical signs observed in the three cases corroborate with those already described for poisoning in horses, which include neurological disorders, apathy, anorexia, dysphagia, weight loss, subcutaneous edema and icterus $[1,10,11,14]$. The distinct variation between the ages of the affected animals is also contemplated in the literature, where this fact is explained by the association of infestation of fields by the toxic plant and the shortage of forage [8,11]. Chronic poisoning signs are the most common in cases of natural poisoning, and the reduction of food intake is the first clinical sign observed, followed by anorexia, weight loss, dysphagia, subcutaneous edema, jaundice, apathy, drowsiness, and in some cases, diarrhea [10,11]. Differently from cattle, equines hardly show signs of tenesmus and ascites [9], presented by equines $\mathrm{A}$ and $\mathrm{B}$, and in some cases may exhibit secondary photosensitization [1]. Signs of hepatic encephalopathy usually comes as a secondary manifestation of chronic liver injury and may lead to depression, compulsive walking in circles or at random, drowsiness, ataxia, and the act of pressing head or body against objects [5], which was observed in equine $\mathrm{A}$.
The macroscopic alterations found in the liver of the three equines were also compatible with what the literature describes for these species, such as lobular pattern accentuation, firm consistency at cut and the presence of hemorrhagic areas [1,7,10]. As for the microscopic analysis of cases of poisoning by Senecio brasiliensis in horses, the alterations are mainly found in the liver and in the central nervous system $[1,10,11]$. As in the cases of the present study, it can be evidenced in the liver hepatic architecture loss, megalocytosis, fibrosis, bile duct hyperplasia, intrahepatic and intracanalicular cholestasis, and hepatocellular degeneration and necrosis $[1,7,10,11]$. While in the brain spongiosis in gray and white matter, degeneration and neuronal necrosis and presence of Alzheimer type II astrocytes can be noticed $[1,7,14]$.

Thus, the diagnosis of poisoning was obtained through the association of the epidemiological study, which indicated the presence of Senecio brasiliensis at the grazing sites where the animals were allocated, the signs observed during clinical care, and the findings of necropsy and histopathology. It is important to point out that the histological lesions were fundamental to establish the diagnosis, which are observed both in cases of natural and experimental poisoning in horses $[1,4,7,9,10]$.

Declaration of interest. The authors report no conflicts of interest. The authors alone are responsible for the content and writing of the paper.

\section{REFERENCES}

1 Gava A. \& Barros C.S.L. 1997. Senecio spp. poisoning of horses in southern Brazil. Pesquisa Veterinária Brasileira. 17(1): 36-40.

2 Karam F.S.C. \& Motta A.C. 2011. Pyrrolizidine alkaloids poisoning in cattle in the state of Rio Grande do Sul, Brazil. In: Riet-Correa F., Pfister J., Schild A.L. \& Wierenga T. (Eds). Poisoning by plants, micotoxins and related toxins. Wallingford: CAB International, pp.175-178.

3 Lucena R.B., Rissi D.R., Maia L.A., Flores M.M., Dantas A.F.M., Nobre V.M.T., Riet-Correa F. \& Barros C.S.L. 2010. Intoxicação por alcalóides pirrolizidinicos em ruminantes e equinos no Brasil. Pesquisa Veterinária Brasileira. 30(5): 447-452.

4 Mendez M.C. \& Riet-Correa F. 2007. Intoxicação por plantas e micotoxinas. In: Riet-Correa F., Schild A.L., Mendez M.C. \& Lemos R.A.A. (Eds). Doenças de Ruminantes e Equinos. São Paulo: Livraria Varela, pp.219-299.

5 Müller J., Schulze M., Herder V., Lautenschläger I., Baumgärtner W. \& Feige K. 2011. Ataxia and weakness as uncommon primary manifestations of hepatic encephalopathy in a 15-year-old trotter gelding. Equine Veterinary Education. 23(1): 5-10.

6 Nobre V.M.T., Riet-Correa F., Barbosa Filho J.M., Dantas A.F.M., Tabosa I.M. \& Vasconcelos J.S. 2004. Intoxicação por Crotalaria retusa (Fabaceae) em equídeos no semi-árido da Paraíba. Pesquisa Veterinária Brasileira. 24(3): 132-143. 
7 Panziera W., Bianchi R.M., Mazaro R.D., Giaretta P.R., Silva G.B., Silva D.R. \& Fighera R.A. 2017. Intoxicação natural por Senecio brasiliensis em equinos. Pesquisa Veterinária Brasileira. 37(4): 313-318.

8 Pearson E.G. 1991. Liver failure attributable to pyrrolizidine alkaloid toxicosis and associated with inspiratory dyspnea in ponies: three cases (1982-1988). Journal of the American Veterinary Medical Association. 198(9): 1651-1654.

9 Pearson E.G. 1999. Liver disease in the mature horse. Equine Veterinary Education. 11(2): 87-96.

10 Pilati C. \& Barros C.S.L. 2007. Intoxicação experimental por Senecio brasiliensis (Asteraceae) em equinos. Pesquisa Veterinária Brasileira. 27(7): 287-296.

11 Riet-Correa F., Soares M.P. \& Mendez M.C. 1998. Intoxicações em equinos no Brasil. Ciência Rural. 28(4): 715722.

12 Santos J.C.A., Riet-Correa F., Simoes S.V.D. \& Barros C.S.L. 2008. Patogênese, sinais clínicos e patologia das doenças causadas por plantas hepatotóxicas em ruminantes e equinos no Brasil. Pesquisa Veterinária Brasileira. 28(1): 1-14.

13 Stegelmeier B.L., Edgar J.A., Colegate S.M., Gardner D.R., Schoch T.K., Coulombe R.A. \& Molyneux R.J. 1999. Pyrrolizidine alkaloid plant, metabolism and toxicity. Journal of Natural Toxins. 8(1): 95-116.

14 Tokarnia C.H., Brito M.F., Barbosa J.D., Peixoto P.V. \& Döbereiner J. 2012. Plantas e micotoxinas que afetam o fígado. In: Plantas Tóxicas do Brasil para Animais de Produção. 2.ed. Rio de Janeiro: Helianthus, pp.147-204. 